\title{
A tradição em dois escopos: patrimônio cultural e sambas de roda
}

\author{
The tradition in two scopes: cultural heritage and sambas de roda
}

\author{
Marcus Bernardes de Oliveira Silveira*
}

RESUMO

O Samba de Roda passou por um processo de patrimonialização nos anos de 2004 e 2005, sendo considerado consecutivamente Patrimônio Imaterial Nacional pelo IPHAN e Patrimônio Oral da Humanidade pela UNESCO. Em função do crescente aumento de políticas públicas no campo cultural, nota-se a intersecção da tradição que deve ser reconhecida e ajudada pelo Estado (representante burocrático da modernidade). Neste ínterim, ocorre um processo de valorização da música (o Samba de Roda) em detrimento dos atores envolvidos no processo. Este artigo, a partir do estudo etnográfico do Samba de Roda na cidade de Conceição do Jacuípe - BA problematiza tanto as dinâmicas de socialização promovidas pelo samba quanto a história da cidade, buscando compreender o processo de construção social da música; apresentando também as relações entre os discursos e práticas de tradição dos grupos pesquisados com a dimensão política do processo de patrimonialização.

Palavras-chave: Patrimônio Cultural. Samba de Roda. Tradição. Políticas Culturais. Culturas Populares

\section{ABSTRACT}

The Samba de Roda went through a heritage process in 2004 and 2005 and was consecutively considered a Intangible National Heritage by IPHAN and Oral Humanity Heritage by UNESCO. Due to the increasing number of public policies in the cultural field, it is possible to observate the intersection of tradition that must be recognized and assisted by the state (bureaucratic representative of modernity). In the mean time, there is a music appreciation process (the Samba de Roda) to the detriment of the actors involved. This work, from the ethnographic study of Samba de Roda in the town of Conceição do Jacuípe - BA discusses both socialization dynamic promoted by samba as the history of the city, trying to understand the process of social construction of music; also presenting the relations between the discourses and

\footnotetext{
${ }^{1}$ Apoio Fundação de Amparo à Pesquisa do Estado da Bahia (FAPESB).
}

- Mestrando em Antropologia Social pela Universidade Federal de Goiás. 
practices of the surveyed group' tradition with the political dimension of the heritage process.

Keyword: Heritage's Policies. Samba de Roda. Tradition. Cultural Policies. Popular Cultures.

\section{Introdução}

As práticas patrimoniais em relação à Antropologia atualmente possuem um aspecto duplo que deve ser evidenciado: o patrimônio enquanto objeto de estudo e enquanto campo de trabalho. Tais concepções implicam em diferentes condutas e visões sobre a realidade social. Desde o Museu Histórico e Nacional (1922), perpassando pelo Serviço do Patrimônio Histórico e Artístico Nacional (1937), Fundação Nacional Pró-Memória (anos1960 a 1980), Instituto Brasileiro do Patrimônio Cultural (anos 1980 e 1990) até chegar ao Instituto do Patrimônio Histórico e Artístico Nacional nos anos 1990, o conceito de patrimônio atrelava-se somente ao plano material, com políticas de tombamento. No Brasil a inserção da noção de patrimônio se delineia no início do século XX, no sentido de construção de uma identidade nacional com a valorização de determinados símbolos, que foram sendo deslocados de sua acepção e significados locais, enquanto pertencentes à cultura popular, para um plano político de construção da nação, enquanto ideologia (ORTIZ, 2006). Nos anos 1990, a Organização das Nações Unidas para a Educação, a Ciência e a Cultura (UNESCO) começa a se preocupar com as "culturas tradicionais" em seus aspectos imateriais também. Tais questões reverberam no país com a criação do Programa Nacional de Patrimônio Imaterial no ano 2000. A partir deste fato há uma incorporação do conceito relativizado de cultura da antropologia no que tange, à ênfase nas diferenças culturais e nos processos dinâmicos de cada povo, ao conceito de patrimônio intangível que será pensado e aplicado nas políticas culturais do IPHAN. Abre-se um novo campo de trabalho para os antropólogos nos processos de patrimonialização em todo país. Entretanto se alguns grupos de intelectuais começam a se articular para criar metodologias e produzir pesquisas dentro das políticas culturais, outros enxergaram tais processos enquanto objeto de estudo e reflexão para problematizar a política patrimonial.

O Samba de Roda ${ }^{2}$ é uma expressão musical afro-brasileira (coreográfica, poética), presente no Estado da Bahia, com maior incidência ${ }^{3}$ na região do recôncavo baiano. Este samba passou por um processo de patrimonialização nos anos de 2004 e 2005, sendo considerado consecutivamente Patrimônio Imaterial Nacional pelo IPHAN e Patrimônio Oral da Humanidade pela UNESCO. A

\footnotetext{
${ }^{2}$ Quando grafado em letra maiúscula e no singular, o Samba de Roda é referente ao Patrimônio Cultural Brasileiro. Quando utilizado no plural é indicativo de destaque para as diferentes tradições dos sambas de roda.

${ }^{3}$ Dentro do território baiano deve-se destacar também a presença do samba de roda na Chapada Diamantina e no sertão da Bahia. A cidade de Riachão do Jacuípe já conta o Festival Regional de samba de roda de Riachão do Jacuípe. Nesse festival participam grupos das cidades de Irará, Conceição do Coité, Ipirá, Itaberaba, São Domingos e Riachão do Jacuípe. Com exceção de Irará, nenhum desses grupos estão registrados na Associação de Sambadores e Sambadeiras do Estado da Bahia (ASSEBA). Mesmo em caráter migratório existe a presença do samba de roda no Ciclo de Reis em Goiânia (IKEDA, 1994) e Curitiba.
} 
questão posta são as relações existentes entre o discurso acadêmico entrelaçado aos processos políticos de patrimonialização. Para um bem ser considerado patrimônio o primeiro passo deve ser o lançamento de um projeto de candidatura com pesquisas detalhando as características culturais daquele bem. Se uma manifestação cultural contar com um grande número de pesquisas já se sobrepõe a outras.

Em se tratando de estudar as dinâmicas entre culturas populares e patrimônio é importante compreender que diferentes concepções de tempo engendram diferentes formas de memórias. A memória coletiva entendida como o meio de integração e ressignificação de práticas culturais dentro do universo das culturas populares é responsável por manter as características de pertencimento a um grupo. Halbwachs (1990) atrela o ato de recordar à noção de grupo. A memória se conserva no grupo e é tratada como um conjunto de acontecimentos compartilhados pelos membros do mesmo. Ela possui uma característica de exterioridade (operacionalização) em um processo de interiorização (socialização), justamente por ser algo compartilhado. Lembranças assim, reconhecidas e reconstruídas. A memória musical é entendida aqui como uma ferramenta analítica para compreender a história e o lugar do samba em Conceição do Jacuípe no estado da Bahia. Através da memória coletiva dos grupos (Raízes da Pindoba e Coisas de Berimbau), será problematizado tanto as dinâmicas de socialização promovidas pelo samba quanto a própria história da cidade, buscando compreender o processo de construção social da música.

Destarte a própria discussão de memória coletiva perpassa pelo âmbito da tradição. Segundo Vansina "o corpus da tradição é a memória coletiva de uma sociedade que se explica a si mesma" (VANSINA, 2010, p. 140). Pensar uma concepção de tradição mais crítica é elaborar uma análise a partir do empírico, construindo um conceito a partir do campo. Em função do crescente aumento de políticas públicas no campo cultural, vê-se a intersecção da tradição que deve ser reconhecida e ajudada pelo Estado (representante burocrático da modernidade). Neste ínterim, ocorre um processo de valorização da música (o Samba de Roda) em detrimento dos atores envolvidos no processo. Como estratégia discursiva, apresento primeiro a cidade (universo empírico da pesquisa) mesclando as informações políticas e econômicas disponibilizadas por instituições do governo, bem como as memórias dos grupos envolvidos na pesquisa. Os dois grupos de sambas de roda da cidade são apresentados concomitantes ao processo de patrimonialização.

A pesquisa ocorreu nos anos de 2011 a 2014, empregando a abordagem metodológica da observação participante como uma forma de aprofundamento ao universo dos sambas de roda. Entrevistas semiestruturadas foram feitas no sentido de explorar objetivos mais específicos. Contudo o conhecimento compartilhado produzido nesta etnografia é fruto desta convivência com os grupos, participação em reuniões, apresentações e ensaios. Durante esse tempo convivi principalmente com Tonho do Samba (Raízes da Pindoba), Mestre Aloísio (Coisas de Berimbau) e Marcos "Brother" luthier da cidade e neto de uma figura central desta musicalidade em Conceição do Jacuípe. Neste sentido, as falas incorporadas na etnografia são dos mestres e líderes dos grupos que são apresentados aos poucos, com suas vozes compondo o quadro da cultura popular 
da cidade. As falas são sempre identificadas, inclusive ressaltando o mês e ano, bem como o grupo que o sambador faz parte. Em reuniões com os sambadores e sambadeiras foi discutido em conjunto os temas relevantes a serem escritos e descritos na etnografia.

\section{Os sambas de roda em Conceição do Jacuípe}

Conceição do Jacuípe é um município do Estado da Bahia que se localiza a cerca de 97 quilômetros da capital baiana Salvador e a 28 quilômetros de Feira de Santana. Considerada então como um dos municípios que fazem parte da nascente Região Metropolitana de Feira de Santana. A cidade possui uma área territorial de $117.559 \mathrm{~km}^{2}$ situada nas terras baixas no rio Jacuípe. O início do seu povoamento remonta aos séculos XVII e XVIII, inseridos no processo de expansão da indústria canavieira no período colonial, com a instalação de engenhos de açúcar. No final do século XIX começa a se estruturar um arraial naquele território, cujo nome remete a sua localização: Arraial de Baixa (Baixada) do Jacuípe. Neste período Santo Amaro despontava como principal referência para os incipientes povoados que iam se formando. No início do século $X X$, começa a se desenvolver uma feira livre naquele arraial, onde se vendiam produtos agrícolas provavelmente das roças que se situavam dentro das terras do engenho, mas que tinha a peculiaridade de ser encerrada com sambas e batuques. A feira era então frequentada por pequenos produtores agrícolas (que também eram músicos e capoeiristas), provavelmente escravos libertos já que legalmente a instituição escravocrata fora abolida, mas ainda deveriam estar ligados as terras dos senhores de engenho. Além da comercialização dos produtos agrícolas, verifica-se uma intensa atividade musical, tanto em venda de instrumentos - tambores artesanais feitos de oco de madeira, pandeiros com couros de animais, berimbaus (a região é propícia para o desenvolvimento de plantas cujo o fruto é a cabaça, matéria-prima para a confecção do instrumento) - quanto na finalização das feiras ao som dos sambas de roda. A feira então passa a ser conhecida como Feira do Berimbau, utilizando a palavra "berimbau" como síntese do complexo cultural que se desenvolvia na feira. Um povoado começa a se erigir em torno da feira, estabelecendo uma intensa ligação política com Santo Amaro. Muitos políticos, secretários, juízes residiam no Povoado do Berimbau (ou tinham nascido no povoado) e trabalhavam na cidade de Santo Amaro.

A feira acontece até hoje todas as terças e sábados. Substancialmente o caráter da feira é voltado para os produtos da agricultura familiar, permanecendo a venda da farinha de mandioca e produtos derivados como o beiju ${ }^{4}$. As Casas de Farinha são muito comuns na cidade. As musicalidades que originaram o nome da feira não acontecem ritualmente ao final da labuta, porém a feira historicamente foi canalizadora de várias tradições populares que se desmembraram nas

4 "Bolo de massa de mandioca ou de tapioca, do tupi mbeiú, o enroscado, o enrolado, alimento característico indígena e amplamente descrito pelos cronistas coloniais no séc. XVI" (CASCUDO, 1998, p. 153). 
manifestações da cultura popular da cidade com o desenvolvimento da tradição dos sambas de roda, na construção artesanal de instrumentos, nas Cantorias de Reis, na Lapinha, no artesanato, na culinária.

Em 1953 pela Lei № 628, o Povoado do Berimbau, oficialmente torna-se Vila de Conceição do Jacuípe, pertencente a Santo Amaro. O novo nome, dado impostamente pelas autoridades políticas, é uma referência à Padroeira da cidade Nossa Senhora da Conceição em conjunto com o nome do rio Jacuípe. Em 1961, com o sancionamento da Lei № 1.531, a vila se emancipa enquanto cidade, permanecendo o nome de Conceição do Jacuípe ${ }^{5}$. A mudança do nome da cidade evidencia o caráter autoritário das figuras políticas imersas em uma ideologia racista discriminatória da época. Uma cidade deveria então fazer referência em seu nome a uma entidade católica, branca, do colonizador e não, a um aspecto cultural da população majoritariamente negra da cidade. Contudo Berimbau (enquanto cidade) possui uma característica de insurgência. Mesmo com a mudança do nome, os habitantes reconhecem a existência de dois nomes: um oficial e o outro que eles se identificam historicamente. Tanto que a população atual comumente denomina a cidade como Berimbau nas conversações cotidianas. O nome Berimbau, mesmo com as tentativas de deslegitimação, continuou conectado a identidade local. O exemplo pode ser evidenciado em outras esferas, como o nome das ruas. Mesmo com a adoção de nomes oficiais, de cidadãos tidos como importantes para a cidade, os primeiros nomes que possuem uma historicidade com 0 desenvolvimento do local se sobrepõe à oficialidade. A atual Rua Juvêncio Dias é referendada como a "Rua do Garrancho", porque antigamente a rua era cheia de árvores secas com pequenos caminhos, onde as pessoas passavam e se arranhavam nos galhos secos. Então quando alguém chegava ao seu destino, através dessa rua, outra pessoa já sabia em função dos arranhões que ela tinha passado pela "Rua do Garrancho". É um traço cultural interessante em que as pessoas reconhecem a existência dos dois nomes, contudo ao conhecer a historicidade do primeiro nome não oficial, as pessoas o empregam cotidianamente. O nome já está inserido na lógica cultural que referenda e identifica os espaços da cidade.

Por ter pertencido e estar vinculado historicamente a Santo Amaro, Berimbau culturalmente sofreu influências desta região. Segundo Mestre Aloísio ${ }^{6}$, o Samba de Roda executado pelo seu grupo Coisas de Berimbau (o nome do grupo faz alusão justamente às tradições populares perpetradas na história da cidade) é o "Santo amarense", "Samba de Beira-Mar", "Samba Chula" ou "Samba da Boca do Recôncavo". A Superintendência de Estudos Econômicos e Sociais da Bahia (SEI) enquadra Conceição do Jacuípe como pertencente ao território do Portal do Sertão. Geograficamente a região do Recôncavo da Bahia abarcaria os municípios que estão no entorno da Baía de Todos os Santos. Contudo estas determinações constituem uma finalidade política e econômica em fragmentar o estado em espaços com fronteiras bem delineadas e classificar os mesmos tentando perceber similitudes (climáticas, geográficas, econômicas) para a construção de políticas territoriais de desenvolvimento. A dimensão cultural é sobredeterminada em função de

\footnotetext{
${ }^{5}$ Segundo o IBGE referente a dados históricos do município.

${ }^{6}$ Entrevista concedida em quatro de janeiro de 2014.
} 
outros interesses. Neste sentido, em termos culturais e pensando a partir do desenvolvimento de distintas tradições do samba de roda, Conceição do Jacuípe, assim como Amélia Rodrigues e Terra Nova são identificados como pertencentes à região do recôncavo da Bahia. A partir de Coração de Maria, que faz fronteira com Conceição do Jacuípe pelo Rio Pojuca, abarcando cidades como Irará e Riachão do Jacuípe, a tradição do Samba de Roda é caracterizada como "sertaneja", proveniente do "Sertão" e, portanto, diferente da tradição de Samba de Roda desenvolvida em Berimbau.

\section{Casa do samba Mestre Domingos Saul}

Em 14 de agosto de 2011 foi inaugurada a Casa do Samba Mestre Domingos Saul em Conceição do Jacuípe. Em conjunto com outros quatorzes municípios, estas Casas do Samba compõem a Rede do Samba de Roda da Bahia coordenado pela Associação de Sambadores e Sambadeiras do Estado da Bahia $^{7}$ (ASSEBA). Esta diretriz organizacional se coaduna com o Plano de Ação desenvolvido para a salvaguarda do Samba de Roda em quatro eixos: organização, transmissão, difusão e documentação. A ASSEBA em reunião com o grupo Coisas de Berimbau explicitou a necessidade de criação de uma Casa de Samba na cidade. Mestre Aloísio alugou uma casa na Rua Teodoro Sampaio, no entanto o espaço era muito pequeno e outra casa foi alugada, na mesma rua em que o sambador reside, na Rua Sete Abril. Esta localização tem uma importância histórica para o Samba de Roda em Berimbau.

A reza era aqui nessa rua (rua sete de abril). Quando cheguei o samba já tinha começado. Mas eu nunca tinha vindo nessa rua, ninguém... não me conhecia, não sabia d'aonde eu era, não sabia d'onde eu vim, nada. Era um volume sem guia. Eu cheguei na janela, me debrucei. E é vai o samba. $O$ dono da casa quando sambava, ele não largava o cavaquinho lá na mesa, ele saía com o cavaquinho na mão. Depois ele encarou assim e disse: "ô garoto", veja que eu tava pequeno ainda, "ô garoto, você há muito tempo que tô lhe vendo encostado aí na janela, você gosta do muquém ${ }^{8}$ ?" Eu disse, eu bato um pandierinho9. Ele disse: "entre pra cá". Aí eu arrudiei, entrei. Aí comecei. É vai eu devagarzinho. Quando foi mais tarde o dono da casa disse: "Mas rapaz, você viu o que acontece? O que a gente tava perdendo? O menino é

\footnotetext{
${ }^{7}$ Em abril de 2005 é criada a Associação de Sambadores e Sambadeiras do Estado da Bahia (ASSEBA) como um novo mecanismo de representação para os sambadores e sambadeiras neste quadro político do Patrimônio

${ }^{8}$ Apelido para se referir ao samba.

${ }^{9}$ Diminutivo para se referir ao instrumento pandeiro.
} 
entendido". É esse Domingos de Saul que eu tô contando a história. (MESTRE ALOÍSIO, 14 de dezembro de 2013).

A homenagem ao Mestre Domingos de Saul está ligado ao reconhecimento histórico da vida de Domingos Júlio dos Santos e a influência do mesmo no Samba de Roda em Berimbau. Saul Moreira era o nome de seu pai (Maria Júlia, a mãe), com quem aprendeu as tradições do samba, logo a referência a Saul no seu nome diz respeito a uma identificação como filho de alguém. Apesar do nome da casa não trazer a preposição de, Casa do Samba Mestre Domingos Saul, no trabalho de campo os grupos se referiam a ele como Domingos de Saul.

Segundo Zilda ${ }^{10}$ filha de Domingos de Saul, seu pai nasceu em Bela Vista ${ }^{11}$ em princípios do século $\mathrm{XX}$, uma roça identificada como pertencente à Berimbau, já que está localizada antes do rio Pojuca que faz divisa com Coração de Maria. Assim como o pai, Domingos de Saul era marceneiro e carpinteiro. Ele trabalhava no Engenho do Cipó $^{12}$, com a desativação desse engenho e com o dinheiro da indenização, comprou algumas terras. Sua casa foi construída na Rua Sete de Abril, mesma rua onde está localizada a Casa do Samba da cidade. Além das atividades mencionadas, Domingos de Saul cultivava produtos agrícolas nas suas terras (banana, mandioca) e vendia na feira do Berimbau. O transporte utilizado era de tração animal. Também era capoeirista, instrumentista (seu instrumento principal era o cavaquinho) e construía instrumentos de percussão e cordas artesanalmente. Ele era responsável pelos sambas que aconteciam após as feiras; sua esposa Dona Glória era doceira e pandeirista. Domingos de Saul tem uma influência fundamental e familiar nos dois grupos de Samba de Roda existentes em Berimbau (Raízes da Pindoba e Coisas de Berimbau). E se normalmente os estudos relacionam o Samba de Roda aos Carurus de São Cosme e Damião (IPHAN, 2007), em Berimbau as tradições do samba estão vinculados também a outra festividade do catolicismo popular: a Cantoria de Reis.

\section{"O Reis"}

A "Cantoria de Reis", "Folia de Reis", "Festa de Reis", ou simplesmente "o Reis" como será tratado aqui, é uma manifestação cultural europeia trazida pelos portugueses na colonização. Difundida por toda a península lbérica eram comuns as visitações nas residências entoadas por cantigas e o recebimento de presentes. Seis de janeiro é oficialmente o dia dos Reis Magos pela

\footnotetext{
${ }^{10}$ Entrevista concedida em 14 de dezembro 2013

11 Foi também referendado durante a pesquisa que Domingos de Saul nasceu na Fazenda Lagoa dos Porcos. Hoje estas terras foram divididas em várias fazendas menores que se localizam na zona rural de Conceição do Jacuípe. Contudo, na época do nascimento de Domingos estas terras pertenciam ao Doutor Gastão Pedreira.

${ }^{12} \mathrm{O}$ Engenho do Cipó pertencia ao Coronel Aurélio Pinto.
} 
Igreja Católica, no qual se rememoram os presentes trazidos pelos Reis Baltazar, Belchior e Gaspar, a peregrinação e as alegrias do nascimento do messias (PERGO, 2007). O contexto brasileiro, a partir do desenvolvimento desta manifestação em vários lugares do país, engendrou variações regionais quanto ao período, os tipos de músicas, os rituais. Apesar das variações, a "Folia de Reis" pode ser entendida como uma manifestação tradicional do catolicismo popular.

Ikeda (1994) estudou o Ciclo de Reis em Goiânia, tentando entender o "viver rural" em uma "moderna" cidade brasileira. O autor determina três tipos de folias: o sistema mineiro, o sistema baiano e o sistema misto. A folia acontece no período de 24 de dezembro a 06 de janeiro. Os grupos de foliões visitam as casas, portando bandeiras de identificação e angariando "esmolas" para a Festa de Reis (no dia 06 de janeiro). Os donos das casas são comunicados das visitas e as "peregrinações" ocorrem entre os bairros. Foram constatadas musicalidades diferentes para cada sistema, e no sistema baiano os grupos tocavam sambas de roda.

O ritual do "Reis" que acontece em Berimbau parece diferir em muitos aspectos. "O Reis" acontece até os dias de hoje na cidade, porém a manifestação descrita aqui foi relatada pelos grupos rememorando as antigas Cantorias de Reis na cidade e região. A folia estudada por Ikeda, além de evidenciar as relações existentes entre Samba de Roda e Folia de Reis que foram levados por baianos para Goiânia, permitirá mostrar as peculiaridades do "Reis" em Berimbau, por comparação.

"O Reis" começava em Berimbau no dia 06 de janeiro e muitas vezes terminava nas vésperas da Semana Santa em abril. As visitações nas casas poderiam ser avisadas (Reis Avisado) ou não (Reis de Surpresa ou Reis Roubado). Cada forma de visitação exigia uma organização diferente. Sendo avisado, isto implicava que o dono da casa deveria arcar com as despesas da festa. Se "o Reis" não era avisado com antecedência para o dono da casa, cabia às pessoas que estavam levando "o Reis" organizar a festa. Cada pessoa ajudava no que podia para arrumar comida e bebida para todos. Além do dono da casa, até os donos de venda ${ }^{13}$ eram acordados para comprar café e biscoito para alimentar as pessoas. Outras comidas e bebidas típicas da festa era a galinha cozida e a cachaça feita em alambique. "O Reis" percorria longas distâncias, abarcando regiões que hoje são municípios distintos. O grupo de até cinquenta pessoas fazia estes trajetos a pé ou, quando conseguiam, com um caminhão "pau de arará". Com o "balaio" de comidas e bebidas pronto, restava seguir em silêncio até a casa em que seria levado "o Reis", que apesar da surpresa de não esperar aquela festa naquele dia, era uma pessoa da comunidade que partilhava e entendia o ritual. Para Tonho do Samba (Raízes da Pindoba) "o samba é o Reis em segredo". Os músicos estavam empunhados então com violas, cavaquinhos e pandeiros. Os pandeiristas levavam uma gazeta (jornal) para queimar e fazer fogo para afinar o instrumento. Aquelas pessoas então se aproximavam da casa (sempre à noite) e cantavam "o Reis":

${ }_{13}$ Termo que se refere aos pequenos mercados típicos de cidades do interior da Bahia que vendem desde produtos de higiene à alimentação. 
Ô de casa, Ô de fora

Maria vai ver quem é

É um cantador de Reis

Mandado por São José

Cantar Reis não é pecado

Porque São José também cantou

São José também chorou

Vendo o seu filho morto

Pregado numa cruz, pro santo amor ${ }^{14}$

O dono da casa então abrindo as portas para aqueles que estavam levando "o Reis" para sua casa, iniciava a festa que duraria até o outro dia de manhã. Domingos de Saul em conjunto com sua família foram apontados como as principais figuras da tradição de "Reis" na cidade. A festa começava então por volta das $22 \mathrm{~h}$. O horário da meia noite, durante "o Reis", apresenta dois significados aparentemente antagônicos, mas por certo complementares. Toda vez que Domingos de Saul estava tocando em um "Reis", quando chegava o horário de meia noite, ele parava de tocar, abraçava seu cavaquinho e fica quieto por um tempo. As pessoas ao redor pensavam que estava dormindo ou descansando. Porém, conta os sambadores que o conheciam, que ele estava rezando, já que acreditava que se deveria agradecer e pedir bênçãos no início do dia. Uma atitude diferente é de outra figura desse mesmo tempo. Segundo Mestre Liodoro ${ }^{15}$ (Coisas de Berimbau), o seu tio (Chico Miúdo que tocava violão) nesse mesmo horário, mudava o jeito de tocar e brincava dizendo que estava tocando o "sambinha do Cão".

O final da festa, já de manhã, era terminado muitas vezes com o "Coco". Este consiste de versos entoados apenas ao som da viola (ou cavaquinho) e o som dos pés batendo no chão.

Tava ralando o meu coco

Minha mulher pra morrer

\footnotetext{
${ }^{14}$ Esta versão foi construída como uma síntese das versões apresentadas durante as entrevistas.

${ }^{15}$ Entrevista concedida em 14 de dezembro de 2013.
} 
Antes eu quero que ela morra

De que meu coco perder

O coco pra nascer coco

Precisa ser ralado em culé (colher)

O homem pra nascer homem

É preciso ter quatro mulé (mulher) ${ }^{16}$

Ô rala o coco

Sacode a colhé (colher)

Primeiro os homi (homem)

Depois as mulhé (mulher) ${ }^{17}$

Os versos retratam a estrutura do patriarcado em que possivelmente o próprio Samba de Roda ou musicalidades que influenciaram o mesmo foram constituídas. Os sambadores identificam que o samba na cidade foi transmitido pelos seus antepassados que eram escravos e trabalhavam nos engenhos da região. Aquela sociedade colonial estabelecia e determinava os lugares e papéis de cada indivíduo. Ser escravo e ser mulher era uma dupla espoliação. O "Coco" acontecia no final das festas. Era costume que a casa deveria ser limpa antes que o grupo fosse embora e tal atividade de limpeza doméstica pertencia ao universo feminino. Neste sentido as mulheres poderiam não estar presentes quando o "Coco" acontecia, sendo os seus versos (enquanto informação histórica) esclarecedores desta dupla expropriação da mulher negra no contexto colonial.

Em Berimbau, portanto, há uma profunda relação entre os sambas de roda e a Cantoria de Reis que se estrutura na história da própria cidade que possui uma forte relação com o catolicismo. Além disso, os dois grupos da cidade foram constituídos e pensados enquanto grupos em Cantoria de Reis.

${ }^{16}$ Versos transmitidos por Liodoro em entrevista no dia 14 de dezembro de 2013

${ }^{17}$ Versos transmitidos por Tonho do Samba em entrevista no dia 06 de dezembro de 2013 


\section{Coisas de berimbau e Raízes da pindoba}

A formalização dos grupos Coisas de Berimbau e Raízes da Pindoba constitui um fenômeno recente. Em determinadas festividades como "o Reis", aniversários, carurus de promessa no mês de setembro, as pessoas da cidade, participantes dessa comunidade que vivenciava as tradições do samba de roda, se reuniam em torno da música. Não existia a ideia de um grupo fixo, com papéis e instrumentos determinados. Existiam sambadores e sambadeiras, que partilhavam das mesmas tradições e, se organizam durante estas festividades. O que não quer dizer que eram fenômenos espontâneos, no sentido ingênuo do termo. Os sambas, as rezas, os Carurus, "o Reis" são manifestações pensadas e organizadas como já foi exposto. A história dos dois grupos remete a uma influência externa para a formatação e nomeação de um conjunto de Samba de Roda.

O grupo Coisas de Berimbau é o mais antigo da cidade, tanto em função dos seus participantes (a maioria idosos), quanto de registro na ASSEBA. Existe uma grande variação e inconstância de pessoas no grupo que se torna complicado saber o número exato de participantes e a função de cada um. Certo mesmo são os três mestres: Aloísio, Cristóvão e Liodoro. Este último era fundador do extinto grupo Filhos das Lages, porém por desinteresse dos componentes o grupo se desintegrou. Coisas de Berimbau possui um CD gravado pelo projeto Pontão de Cultura da ASSEBA; neste consta a seguinte relação quanto aos músicos: Jorginho (Pandeiro I), Liodoro (Pandeiro II), Salvador (Pandeiro III e vocalização), Cristóvão (Pandeiro IV e vocalização), Edmilson e Manoel (Timbau), Nair (Triângulo e vocalização), Cabrito (Violão), José (Cavaquinho), Aloísio (Puxador de samba). No geral, contando sambadores e sambadeiras, o grupo possui cerca de 20 pessoas. A criação do grupo com o nome Coisas de Berimbau aconteceu em uma Cantoria de Reis. Uma figura pública da cidade (incentivador da cultura local) sugeriu àquelas pessoas que animavam "o Reis" a formação de um grupo, sugerindo inclusive o nome. Mestre Aloísio assumiu desde então a coordenação do grupo. O próximo passo foi o registro na ASSEBA. A necessidade de um articulador, de uma figura política para resolver as demandas burocráticas do grupo em relação à associação, mostrou-se fundamental.

Mestre Aloísio nasceu em Terra Nova, só na sua infância (aos 8 anos) foi morar em Berimbau onde vive atualmente. Conheceu o samba através dos pais, sua mãe tocava pandeiro e o pai era sanfoneiro. Seus pais não tinham com quem deixar os filhos, então os levavam para o samba. Antigamente com poucas pessoas se fazia o samba. $\mathrm{Na}$ adolescência já viajavam pelas regiões vizinhas com um amigo tocando nas rezas e nas festas, "duas pessoas cantando e tocando mais as sambadeiras, tava feito o samba"18. O necessário então para o samba em termos instrumentais era o pandeiro, o tambor ${ }^{19}$ e o cavaquinho. Estes três instrumentos do decorrer da pesquisa mostraram-

\footnotetext{
${ }^{18}$ Mestre Aloísio, entrevista concedida em quatro de janeiro de 2014.

${ }^{19}$ Este tambor, também chamado tamborinho, era construído artesanalmente feito com oco de madeira e couro de alguma animal (raposa, bode, jiboia) esticado batido com brochas. Os pandeiros também tinha esse mesmo processo artesanal, sendo necessário o fogo para afinar o instrumento.
} 
se característicos da tradição do Samba de Roda na cidade. Ao longo do trabalho de campo, ouvindo diferentes pessoas (mestres, sambadores e sambadeiras, comunidade envolvida com o samba), o cavaquinho aparece como principal instrumento entre os cordofones. Mesmo após as oficinas de construção da viola machete ${ }^{20}$ organizada pela ASSEBA ${ }^{21}$, é notório que nenhum dos dois grupos da cidade possuam o instrumento. Na tradição do Samba de Roda em Berimbau, a viola machete não era conhecida pelos grupos ${ }^{22}$. Muitos só descobriram sua existência pósprocesso de patrimonialização.

O Raízes da Pindoba também se constitui enquanto grupo a partir de uma Cantoria de Reis em fevereiro de 2007. O grupo foi organizado por Tonho do Samba e um amigo a partir dos sambas que faziam nos aniversários, nos Reis. A princípio o nome do grupo remete a localidade em que a maioria dos componentes morava, no bairro conhecido por Pindoba em Conceição do Jacuípe. Porém o nome do grupo, segundo Tonho do $\mathrm{Samba}^{23}$, remete à árvore chamada pindoba que tem relações interessantes com a região. A árvore é matéria-prima para construção de vassouras que são utilizadas nas Casas de Farinha da cidade, para varrer a farinha do forno, quando esta termina de secar. Da sua árvore também se consome o fruto, chamado "nicuri" ${ }^{24}$. Com o tempo, Tonho do Samba assumiu a liderança do grupo e com ajuda da sua esposa registrou o grupo na ASSEBA. Ao contrário do Coisas de Berimbau (que apesar das variações das pessoas nas apresentações, possui um número relativamente fixo), os componentes do grupo Raízes da Pindoba não são fixos. A maioria dos músicos toca por "cachê" ${ }^{25}$ e o grupo não possui sambadeiras. O único componente fixo do grupo nesse sentido é o próprio Tonho do Samba. Além de organizar as apresentações, é o vocalista e compositor do grupo e também possui os instrumentos musicais.

Tonho do Samba (José Antônio dos Santos Conceição) nasceu em 1971 na zona rural do município de Coração de Maria. Passou a infância em Santo Amaro e na adolescência foi morar em Berimbau. Suas primeiras lembranças do samba remontam ao período que morava na roça e ele ia com seus pais para as rezas animadas com Samba de Roda. Seu pai tocava repique e sua mãe, assim como Dona Glória e a mãe de Mestre Aloísio, tocava pandeiro. Outra característica interessante do samba em Berimbau é em relação às mulheres. Em outras cidades como Cachoeira e São Felix, por exemplo, as mulheres quando tocam algum instrumento são as tabuinhas ${ }^{26}$ ou 0

\footnotetext{
${ }^{20}$ A viola machete é um cordofone de dez cordas entendido como característico do Samba de Roda no Recôncavo da Bahia. Uma das diretrizes do plano de Salvaguarda do IPHAN é justamente no processo de revitalização do instrumento. Ver Nobre (2008) e IPHAN (2007).

${ }_{21} \mathrm{Um}$ dos alunos desta oficina é residente em Berimbau e responsável atualmente pela construção das violas machetes da ASSEBA. O seu nome é Marcos Luis dos Santos (conhecido como Marcos Brother) e ele é neto de Domingo de Saul.

${ }^{22}$ Foi mencionado por apenas uma pessoa, Mestre Liodoro, a existência de uma viola "regra inteira" de 24 cordas, tocado pelo falecido irmão da sua sogra. Também foi relatado a existência do banjo, do bandolim e da sanfona de oito baixos chamada de "pé de bode".

${ }^{23}$ Entrevista concedida em fevereiro de 2012

24 O "nicuri" serve de alimento para a população da região com o chamado "fufu de nicuri". "Pegava o nicuri, quebrava ele, botava no pilão com um pouco de farinha e açúcar e pau! Tome-le bater no pilão! Aí pegava aquilo ali pra tomar café" (Tonho do Samba; 06 de dezembro de 2013).

25 O "cachê" se refere normalmente a uma quantia em dinheiro que cada músico recebe por apresentação.

${ }^{26}$ Dois pedaços de madeiras que são batidos um no outro, compondo a linha rítmica do samba.
} 
prato-e-faca. Em Berimbau nota-se a presença de mulheres tocando outros instrumentos como o pandeiro e o triângulo27.

Um momento de socialização no samba, em relação a processos de aprendizagem que foi identificado, eram os intervalos no samba. Nesse momento as crianças tinham a oportunidade de se aproximar dos instrumentos e "brincar", tentando reproduzir aqueles sons que estavam ouvindo. Mas isto não quer dizer que era uma atividade respaldada pelos mais velhos, normalmente os pais não ensinavam diretamente aos filhos. Mestre Aloísio afirma que não teve nenhum professor e nem seu pai teve. Os adultos não ensinavam às crianças, elas aprendiam observando, "pela cabeça". "Eu fui sempre vendo e aprendi. É o dom. Me mande fazer outra coisa além do samba que eu não sei não. Eu só escuto o samba, só toco o samba"28. Contudo a lógica atual de transmissão para as novas gerações apresenta modificações estruturais. Se no passado, a criança entrava em contato com o samba e experimentava a música em seu próprio contexto ritual; hoje, com os planos de salvaguarda e as possibilidades de extinção desta musicalidade (mesmo que a preocupação pareça remeter mais aos discursos de autenticidade da cultura popular e de uma constante "retórica da perda"), a transmissão ocorre via projeto de oficinas mirins. Na Casa do Samba Mestre Domingos Saul são organizadas aulas de instrumentos para jovens interessados em conhecer o Samba de Roda. As aulas são ministradas pelos componentes do grupo Coisas de Berimbau.

No decorrer da pesquisa, analisando diferentes momentos de performances dos grupos e as oficinas ministradas na Casa do Samba, os instrumentos identificados foram: pandeiro, timbau, triângulo, xequerê, repique, unitário, violão, cavaquinho, castanhola, tabuinha, prato-e-faca e caixa de fósforo.

O grupo Coisas de Berimbau é formado por sambadores e sambadeiras em sua maior parte já idosos, com faixa etária em média de 60 a 85 anos. O tipo de samba do grupo é o "Samba BeiraMar", também chamado de "Santo Amarense" ou "Samba Chula". O "Beira-Mar" se caracteriza pelo canto e resposta; enquanto um sambador "grita" o samba (ou seja, o "puxador", aquela que conduz o repertório e decide quais músicas cantar), o outro sambador (e as sambadeiras também) "rela", responde o que o outro disse, é o chamado relativo que caracteriza as chulas. $O$ grupo utiliza fardas, camisas com o nome do grupo, inclusive as sambadeiras. Os homens trajam estas camisas com a nomenclatura do grupo (de cores verde ou azul) e calças; os mestres (Aloísio, Cristovão e Liodoro) usam chapéus. As mulheres além das camisas mencionadas usam saias rodadas coloridas.

O grupo Coisas de Berimbau se apresenta normalmente com cinco pandeiros, tocados pelos cinco mestres. O pandeiro foi instituído no Brasil via Portugal, era um instrumento popular em toda a Europa no período colonial (REPPOLHO, 2012). Assim como a viola e outros instrumentos de cordas (NOBRE, 2008), é possível que o pandeiro tenha sido trazido pelos jesuítas e apresentados aos escravos em práticas de catequese. No samba, os pandeiros são tocados "numa pancada só",

\footnotetext{
27 "Há indícios de que seja originário do Norte da África (Marrocos)" (REPPOLHO, 2012, p. 96)

${ }^{28}$ Tonho do Samba, entrevista concedida em 06 de dezembro de 2013.
} 
ou seja, no mesmo ritmo e da mesma forma. A posição do instrumento é bem peculiar, sendo tocado na vertical, ao contrário de outros gêneros com o Choro, que o pandeiro é tocado na horizontal. Os improvisos característicos do instrumento acontecem em momentos precisos da apresentação, em que o pandeirista se sobressai em relação aos outros ao "repicar" o instrumento. Esse "repicar" consiste na repetição acelerada de toques no centro do pandeiro com os dedos indicador, médio e anelar. Outros instrumentos que compõem a linha rítmica do grupo são o timbau, o triângulo, o chocalho e as tabuinhas. Estes dois últimos são executados pelas sambadeiras; em algumas apresentações também foi visto mulheres tocando triângulo. Outros instrumentos mencionados são improvisados de utensílios domésticos; sendo tocados por homens e mulheres. Além do prato-e-faca ${ }^{29}$, da caixa de fósforos ${ }^{30}$, existe a castanhola. A castanhola (que nos remete a pensar nos acompanhamentos rítmicos da música flamenca espanhola) é improvisada com duas colheres; seguradas em uma mão pelo polegar e indicador e a outra pelo anelar. Elas são postas viradas uma para cima e a outra pra baixo e, são tocadas com a outra mão e a coxa em movimento constante, marcando o ritmo.

Os instrumentos de cordas "puxam" o samba, para depois entrar o acompanhamento rítmico. Existem dois momentos fundamentais durante o samba que se alternam por toda a apresentação. Quando começa, o samba tem uma característica instrumental. Os músicos se posicionam em um semicírculo que é completado pelas sambadeiras. Quando o "puxador" inicia as chulas, o centro do círculo permanece intocado. Enquanto a letra está sendo cantada, as sambadeiras continuam completando o círculo e cantando. Quando a letra é finalizada, o samba volta a ser instrumental. Nesse momento as sambadeiras vão dançar dentro do círculo, primeiro saudando cada músico, com os passos característicos do chamado "miudinho", onde os pés quase não saem do chão e os seus corpos mais se parecem pêndulos em movimentos suaves. Neste contexto abre-se espaço para o improviso. Além do já citado "repicar" do pandeiro; o cavaquinho e o violão alternam-se em improvisações. Na maior parte da apresentação, o violão exerce a função de acompanhamento nas regiões graves do instrumento, podendo construir acordes ou apenas fazer a marcação. Os solos consistem em variações melódicas ascendentes e descendentes de escalas maiores, principalmente em Sol e Ré, tanto do violão quanto do cavaquinho. Logo o "puxador" começa a entoar outras letras e as sambadeiras retornam ao círculo, os improvisos cessam e esperam o outro momento.

O grupo Raízes da Pindoba, em suas apresentações, é formado por cerca de oito a dez pessoas. O grupo não possui sambadeiras. O samba feito pelo grupo é chamado de "Samba Corrido" que se caracteriza por uma dinâmica mais rápida, tem uma voz principal que não necessita necessariamente de resposta nos versos, mas podem ter a presença de uma segunda voz. Enquanto que no grupo Coisas de Berimbau os músicos permanecem parados, no Raízes da Pindoba os instrumentistas também dançam. Além dos instrumentos já citados, o grupo utiliza ainda

\footnotetext{
${ }^{29} \mathrm{~A}$ faca ao riscar o prato em movimento constante, acompanha ritmicamente o samba.

${ }^{30}$ A caixa de fósforos é também muito utilizada nas rodas de samba no Rio de Janeiro. Consiste em utilizar a caixa vazia com apenas um palito inserido até a metade da caixa. O ritmo é dado pelo som do palito batendo na caixa vazia.
} 
o xequerê $\hat{A}^{31}$, o repique ${ }^{32}$ e o unitário ${ }^{33}$. O grupo pode ser entendido no contexto de transformação que passa o Samba de Roda, no intuito de ocupar novos espaços e novos públicos:

\author{
É melão, é melancia \\ O Samba de Roda chegou na Bahia \\ É melão, é melancia \\ Raízes da Pindoba que contagia \\ Essa mistura tropical \\ O samba é cultura nacional ${ }^{34}$
}

A letra é composição de Tonho do Samba. Nela pode-se identificar a tradição em dois escopos. Os versos não deixam de identificar a realidade rural em que o samba se construiu na cidade de Conceição do Jacuípe e, nem das suas próprias vivências. Tonho do Samba, quando jovem, trabalhava com o pai na lida do campo, para ajudar a família e alimentar os irmãos. Entretanto, outra concepção exposta está ligada ao processo de patrimonialização. "O samba é cultura nacional" sintetiza a assimilação da ideia de que o samba é um patrimônio de dimensões nacionais. O samba de roda, entendido agora como patrimônio, passa a engendrar novos discursos e novas performances.

\title{
"O Parecer"
}

O conceito de tradições inventadas proposto por Hobsbawm e Ranger (1997), embora esteja ligado ao processo de criação dos países na Ásia e África e na constituição dos Estados Nacionais

\footnotetext{
31 'Instrumento feito de cabaça, uma variante do tradicional de 'Aguê' nigeriano. [...] No Brasil é usado nos terreiros de Candomblé e Umbanda, nos maracatus de Nação em Pernambuco com o nome de 'Agbe', que em lorubá significa 'Cabaça', em blocos afros denominados de Afoxés, tendo como maior referência o Bloco Afro ljexá Filhos de Gandhy, da Bahia, e em diversos estilos musicais". (REPPOLHO, 2012, p. 101).

$32 \mathrm{Um}$ tipo de tambor afro-uruguaio, tocado com as duas mãos, uma com baqueta e a outra com a mão (REPPOLHO, 2012).

${ }^{33}$ É um tipo de tambor pequeno, tocado com duas baquetas.

${ }^{34}$ Versos transmitidos por Tonho do Samba em entrevista no dia 06 de dezembro de 2013
} 
europeus, pode ser readaptado às formas como o Estado brasileiro operacionaliza os fenômenos ditos tradicionais e constitutivos de um patrimônio. O termo é assim definido:

\begin{abstract}
Por "tradição inventada" entende-se um conjunto de práticas, normalmente reguladas por regras tácita ou abertamente aceitas; tais práticas, de natureza ritual ou simbólica, visam inculcar certos valores e normas de comportamento através da repetição, o que implica, automaticamente, uma continuidade em relação ao passado. (HOBSBAWM; RANGER, 1997, p. 9)
\end{abstract}

A tradição em dois escopos é evidenciada de forma dialética, levando em consideração às nuances do mundo social, portanto erigida em função do campo de pesquisa. A partir dos grupos estudados (Coisas de Berimbau e Raízes da Pindoba) e da participação em reuniões na ASSEBA foi possível identificar uma tensão (entre grupos de diferentes cidades, entre a coordenação da ASSEBA e os grupos) nos discursos de tradição sobre os (e dos) Sambas de Roda decorrentes da própria dinâmica interna da cultura (já que esta não é estável, portanto mutável e polissêmica), mas também das novas formas de organização em face do processo de patrimonialização. Todo discurso, toda performance é criação social, é inventada e, em certos níveis possuem seus aspectos de arbitrariedade; bem como toda prática que é cotidiana, recorrente e ritual implica em processos de continuidades. O que está sendo posto em questão são as transformações das práticas culturais, através de políticas públicas que instauram a mudança, porém pensando a preservação.

O Registro de Bens Culturais de Natureza Imaterial é o instrumento legal dos processos de patrimonialização do Estado brasileiro. O processo (01450.010146/20-4-60) referente ao Registro do "Samba de roda do Recôncavo baiano" é acompanho de um "Parecer" do IPHAN em relação à candidatura da musicalidade à Patrimônio Cultural Brasileiro. A relatora ${ }^{35}$ entende que o próprio conceito de patrimônio imaterial deve ser construído a partir da aplicação das políticas referentes ao Registro. A visão expressa em relação às justificativas da necessidade de Registro do referido bem, acaba por reificar ideias ingênuas em relação às culturas populares, construindo modelos que não possuem correspondência empírica.

Tratava-se de circunscrever no amplíssimo e difuso contexto do samba brasileiro uma manifestação que fosse espacialmente delimitável, culturalmente relevante e, sobretudo, cuja distinção, no universo musical e

\footnotetext{
${ }^{35}$ Maria Cecília Londres Fonseca, conforme "Anexo 2 Parecer do Relator" (IPHAN, 2007, p. 191-198)
} 
coreográfico tão diversificado do samba, estivesse fundada numa justificativa consistente. (IPHAN, 2007, p. 192).

Uma problemática que também é abordado no "Parecer" são as diferenças entre as sentenças "samba de roda do Recôncavo baiano" e "samba de roda no Recôncavo baiano". A sentença que prevalece tanto no Registro quanto no Dossiê é o "samba de roda do Recôncavo baiano" já que torna a manifestação "espacialmente delimitável". Embora, como demonstrado neste trabalho, existam tradições de Sambas de Roda no estado da Bahia e a própria ideia de "recôncavo baiano" a depender dos critérios abarcam diferentes territórios. Outra questão posta é a de "culturalmente relevante". O Brasil tem dimensões continentais e é feito de múltiplas manifestações culturais que são igualmente significativas. Cada grupo forja sua própria ideia de patrimônio no sentido de importância histórica para o mesmo. E continua o "Parecer":

\footnotetext{
Embora todos esses traços contribuam para distinguir o samba de roda das manifestações contemporâneas mais conhecidas do samba, há um traço enfatizado no texto da instrução que, a meu ver, constitui um dos valores mais significativos dessa forma de expressão da cultura nacional, e que é característico do pagode (em sua versão mais tradicional) e de outras versões do samba brasileiro: a "espontaneidade" de sua ocorrência, construindo-se como uma forma de expressão profundamente internalizada nos indivíduos e grupos que o têm como parte de seu repertório cultural. A própria expressão "o samba acontece" é elucidativa de uma manifestação não ritualizada do samba, contribuindo para relativizar o caráter de espetáculo que o samba brasileiro assume por ocasião dos desfiles carnavalescos. (IPHAN, 2007, p. 194).
}

Como já foi demonstrado, se não existiam grupos formais de samba e sim pessoas que inseridas em um mesmo contexto cultural, se reuniam em festividades diversas com a presença constante desta musicalidade; isso não equivale dizer que os sambas são ou eram "espontâneos". A Cantoria de Reis descrita nos informa o caráter de organização que as festas populares possuem, com papéis e funções determinadas e discutidas. As cantigas entoadas na festa possuem uma ordem; as próprias performances expostas (Coisas de Berimbau) implicam em um ritual que deve ser respeitado, cada instante da "roda" pressupõe condutas bem delineadas.

É evidente que nas pesquisas relacionadas ao processo de candidatura do Samba de Roda à Patrimônio Cultural Brasileiro, buscaram-se aspectos gerais desta manifestação para a criação de 
uma ideia em que o Samba de Roda fosse constante no território do recôncavo. Ao Registro cabe a inscrição de um bem cultural, então é compreensível o escopo voltado para as semelhanças, ao invés das diferenças. Porém na sombra dos modelos universais ficam escondidas as peculiaridades de cada região e, uma realidade empírica que atesta a construção de diferentes tradições de Samba de Roda.

Eu tive num samba em Acupe, naquela época. Por sinal quando cheguei lá, eu me atrapalhei todo. Porque a gente aqui samba é tipo Beira-Mar e lá é Beira-Mar, mas lá samba é Barravento. Barravento é aquele samba que diz o samba, mas não diz a resposta. E a gente aqui diz o samba e resposta, né? E eles lá, eles diz o samba, mas não tem resposta. É mesmo que foguete ruim. Sobe, mas não estoura! (MESTRE ALOÍSIO, 4 de janeiro 2014)

Mestre Aloísio também identifica as diferenças entre o Samba "Beira-Mar", relacionado à Conceição do Jacuípe e o samba do "Sertão" referente às cidades como Irará e Riachão do Jacuípe. Historicamente, as relações estabelecidas entre os indivíduos envolvidos no contexto do Samba de Roda, parecem se restringir às regiões em que esta musicalidade se apresentava semelhante. Assim são destacados, por exemplo, uma intensa interação cultural (nas festividades do catolicismo popular, relações de parentesco) entre Conceição do Jacuípe, Terra Nova, Coração de Maria e Santo Amaro. Nestas regiões se identificam o Samba "Beira-Mar", ou seja, uma conformidade entre as manifestações culturais. Neste sentido, em regiões fora desta circunscrição, o diálogo entre tradições diferentes de Samba de Roda tornava-se mais difícil.

O "Parecer" também destaca o "caráter de espetáculo" que o "samba brasileiro" vivencia através dos desfiles de Carnaval e, que, o Samba de Roda, por seu caráter "espontâneo", estaria inserido em outra lógica. Em decorrência do próprio processo de patrimonialização, o samba de roda passou a ocupar novos espaços de apresentação. Se ele já não tinha esse caráter "espontâneo" pelos motivos referendados acima, a sua própria estrutura de organização se fragiliza em função das demandas atuais.

O samba de roda é o seguinte: hoje tem moço botando em cima do palco e tudo, mas o pessoal não gosta. O pessoal quando a gente faz o samba de roda no chão, aí junta todo mundo. Todo mundo quer brincar. Todo mundo tá gostando, todo mundo quer sambar. E lá em cima não. (MESTRE LIODORO, 14 de dezembro de 2013). 
A apresentação em um palco desestrutura uma das principais características da musicalidade que é a roda; além disso, o próprio palco já representa um caráter de espetacularização. O grupo Raízes da Pindoba, por não ter sambadeiras, se insere nessa lógica sem muitos conflitos. Porém, mais do que uma característica estruturante da musicalidade, ela é um princípio de fortalecimento da solidariedade social entre os indivíduos que é ritualizada nas performances. O relato destaca a aversão ao samba quando o mesmo é apresentado "lá em cima" do palco. É criada uma distância entre sambadores e comunidade.

Em 2005 foi criada a Associação de Sambadores e Sambadeiras do Estado da Bahia como uma demanda política do próprio processo de patrimonialização do samba. Uma questão discutida naquele momento em relação à ASSEBA era "saber se sua atuação contribuirá para a autonomia e o empoderamento crescentes dos sambadores e sambadeiras" (SANDRONI; 2010; 378). Contudo a centralização de uma sede principal em Santo Amaro, mesmo com a posterior construção da Rede do Samba, engendrou o empoderamento em lugares e grupos específicos. A capacidade de articulação política de alguns grupos acabou por estabelecer espaços de privilégios.

\section{Revalidação do título de patrimônio cultural brasileiro}

A reunião ocorrida em sete de dezembro de 2013 na Casa do Samba em Santo Amaro, sede da ASSEBA, objetivou discutir o processo de revalidação do título de Patrimônio Cultural Brasileiro concedido ao Samba de Roda pelo IPHAN em 2004. Esta reunião foi uma consequência do encontro que os coordenadores da ASSEBA tiveram com membros do IPHAN dois meses antes, quando foram informados deste processo de revalidação. Esta é uma diretriz política do IPHAN, todo bem cultural proclamado como patrimônio após 10 anos deve passar por novas pesquisas no intuito de validar se aquele bem continua ou não com o status de patrimônio. A ASSEBA, como modo de participar desse processo de pesquisa, propôs uma reunião com a necessidade de fazer uma auto avaliação da própria associação e da percepção dos sambadores sobre a situação do samba de roda nesses 10 anos. Esta auto avaliação consistiu em um documento enviado ao IPHAN, abarcando assim uma demanda maior dos sambadores da região.

A reunião foi dividida em três grandes momentos. Uma primeira etapa foi a exposição de um dos coordenadores da ASSEBA sobre o objetivo da reunião. Foi explicado aos sambadores e sambadeiras que a cada 10 anos ocorre esse processo de revalidação, sendo necessário fazer uma avaliação desse período, pensando quais os pontos que foram avançados durante este tempo. $O$ plano de salvaguarda contido no Dossiê foi exposto e explicado aos sambadores como metas a serem cumpridas e, a avaliação proposta pela reunião deve ter como base os pontos contidos neste 
plano, a saber, referentes a organização, transmissão, difusão e documentação no contexto do Samba de Roda.

O segundo momento da reunião consistiu na divisão em grupos de trabalhos para uma melhor organização. Cada grupo deveria possuir mais ou menos trinta pessoas, sendo coordenados por articuladores das Casas de Samba. A indicação era de que os indivíduos da mesma cidade ficassem em grupos diferentes para uma maior pluralidade de informações. A ASSEBA foi criada justamente para gerir esse processo de patrimonialização; nos grupos de trabalho deveriam se expor os pontos positivos e negativos da associação. A fala dos coordenadores da ASSEBA era de que suas ações eram pautadas pelo Dossiê e pelas demandas dos sambadores. Nessas discussões dos grupos de trabalho foram ouvidos então os articuladores, lideranças de grupo, mestres, sambadores e sambadeiras.

No terceiro momento da reunião, retornou-se para a sala principal para que os coordenadores dos respectivos grupos de trabalho expusessem as demandas propostas. O primeiro grupo de trabalho, segundo sua coordenadora, destacou mais pontos positivos do que negativos. Outro ponto que deveria ser evidenciado era uma projeção para os próximos 10 anos, caso o título de patrimônio ainda vigore. Nesse sentido três questões foram postas como fundamentais: a saúde dos sambadores, o registro da memória dos mestres e a sustentabilidade dos sambadores. Uma projeção interessante é a necessidade de inserir o samba de roda na mídia (rádio e televisão). Existe a crítica dos sambadores de que alguns grupos são privilegiados no sentido de terem mais espaços para se apresentarem. Alguns grupos já fizeram viagens para o exterior, enquanto outros não saíram da sua região. Este dado novo incute, mesmo sem a intenção, uma lógica de competitividade. Uma musicalidade que tinha como base a integração, o fortalecimento dos laços sociais; agora se insere em um espaço de disputa midiática para ocupar lugares de prestigio em que os próprios discursos de tradição são acionados para legitimar determinados grupos em função de outros.

No segundo grupo de trabalho, os sambadores apontaram a necessidade de conhecer mais as diretrizes do plano de salvaguarda. Segundo o coordenador deste grupo, os sambadores desejam continuar nesse processo de "resgate". Estas demandas foram expostas publicamente pelos seus respectivos coordenadores, apresentando em comum os avanços que o processo de patrimonialização e a ASSEBA trouxeram para o samba de roda. Entretanto, no terceiro grupo de trabalho, no qual estavam presentes Tonho do Samba (Raízes da Pindoba), Mestre Liodoro (Coisas de Berimbau) e a articuladora da Casa do Samba Domingos Saul foram destacados as falhas desse processo. No grupo de trabalho, Tonho do Samba expôs a dificuldade de manter um grupo mirim de samba de roda em função da distância entre a casa das crianças (que fica na zona rural) e a Casa do Samba Domingos Saul no centro da cidade. Outro apontamento foi a dificuldade do grupo em gravar o seu CD, previsto no Dossiê do IPHAN, já que era o único grupo da cidade de Conceição do Jacuípe que não conseguiu a gravação. Outro apontamento foi a necessidade de um maior apoio à Casa do Samba Domingo Saul, já que Mestre Aloísio (Coisas de Berimbau) que paga o aluguel do 
espaço, bem como a demanda e manutenção de instrumentos. Críticas foram feitas à burocratização da ASSEBA que promove várias reuniões, mas com poucos resultados. Alguns articuladores e lideranças de grupo expuseram as dificuldades de manter o samba em suas respectivas comunidades, destacando municípios como Santo Amaro, Cachoeira, São Francisco do Conde e Feira de Santana como espaços privilegiados. Outra questão é a falta de apoio no desenvolvimento de articuladores locais que representariam as Casas do Samba dos diversos municípios que compõem a Rede do Samba. De fato, nas cidades e grupos que não possuem um articulador ativo, participante das reuniões e conhecedor das demandas das suas comunidades, nota-se uma maior precarização nos grupos. Os espaços vistos pelos sambadores (de lugares tidos como marginais) como privilegiados revelam uma intensa atividade política dos grupos e dos articuladores. A figura do articulador é fundamental nesse processo, já que muitos grupos são formados por pessoas muito idosas ou de classe menos abastadas que muitas vezes só possuem o nível básico de educação. A burocratização exigida pela ASSEBA acaba por dificultar a integração entre estas Casas do Samba com a sede em Santo Amaro. A elaboração dos projetos (da ASSEBA e dirigidos ao IPHAN) mostram-se de difícil compreensão para os sambadores e sambadeiras. $O$ articulador e as lideranças de grupos então são figuras centrais nessa ponte entre os grupos e a ASSEBA, logo entre os grupos e as políticas culturais do IPHAN.

Depois das demandas expostas pelos coordenadores, abriu-se espaço para complementações. É fundamental perceber a pluralidade de opiniões, convergindo em alguns pontos, porém em outros assumindo posições antagônicas. Enquanto alguns apontam para a necessidade de ocupar novos espaços (a mídia, por exemplo), outros se preocupam em não esquecer os antigos espaços ocupados (o samba de caruru). Este samba de caruru já apresenta tensões em sua própria constituição atualmente. $O$ fato de um grupo ser convidado para ir tocar em um caruru, algo comum, gera uma tensão em função da indumentária utilizada pelo grupo: a farda. Muitos grupos que fazem parte da ASSEBA, adotaram a prática de confecção de uma camisa com o nome do grupo, uma necessidade de organização resultante desse processo de patrimonialização. O que é exposto na reunião é a intimidação que isto gera nos sambas de caruru, no qual outro sambador fica com receio de pegar um padeiro e tocar.

A tradição em dois escopos é assim identificada nesse jogo de tensões em que o samba de roda é posto. A partir do momento que se organiza formalmente (ASSEBA) e uma nova questão é introduzida: as políticas culturais. A tensão é justamente veiculada ao samba de roda ser patrimonializado por determinadas características tradicionais, que também são vistas na ordem do excepcional; entretanto a dimensão política e burocrática exigida acaba por criar novas performances, novos discursos.

Esse movimento do Samba de Roda, isso é política de Estado. O Samba de Roda é Patrimônio da Humanidade. É Patrimônio Cultural Brasileiro. Vai virar Patrimônio Cultural do Estado da Bahia. Os municípios, alguns já tem Dia 


\begin{abstract}
Municipal do Samba. Já vai ter Dia Nacional do Samba de Roda. Isso tá virando política. Então tocar no caruru, a gente tá nessa questão aí. Continuar fazendo o samba de roda no caruru, mas também sentar na mesa para discutir com o presidente do IPHAN, com o superintendente do IPHAN, com a Ministra da Cultura, com os prefeitos. São dois pontos. É por isso que nós temos aqui alguns fóruns. Por isso que a gente conversa com os mestres de uma forma. É por isso que a gente conversa com as lideranças de grupos de uma outra forma. E com os articuladores, o tom tem que ser outro. A nossa posição é política. (ROSILDO, 7 de dezembro 2013).
\end{abstract}

A questão política é então uma realidade atual para os grupos de Samba de Roda. É certo que o processo de patrimonialização traria consequências desse nível e a própria organização em uma associação já demanda espaços de reuniões, discussões e metas. A ASSEBA proporcionou uma maior interação entre grupos de distintas cidades e, o conhecimento de outras tradições do Samba de Roda é exemplificado como um dado positivo. Cabe à ASSEBA e aos grupos antigos e os que estão para se formar, "administrar" esta tensão promovida pela tradição em dois escopos, ampliando a ideia local de comunidade agora expressa em nível de associação.

\title{
Considerações finais
}

Os discursos de tradição vistos em dois escopos inserem-se nesta problemática de pensar o Samba de Roda enquanto Patrimônio Cultural Brasileiro. Por um lado existem práticas culturais dinâmicas que se ressignificam historicamente e, por outro, uma política preservacionista que acaba por inserir um dado novo naquela cultura, instaurando a mudança pensando, porém, na preservação. A memória coletiva, neste sentido, referendada a partir dos grupos permite a análise de forma totalizante, articulando a construção social do Samba de Roda à história local da cidade numa perspectiva histórica, cultural e política.

A memória coletiva dos grupos revelam especificidades interessantes sobre as tradições dos Sambas de Roda no recôncavo da Bahia. É fundamental neste momento político do Samba de Roda, trabalhos que atestem a pluralidade de tradições que esta musicalidade desenvolveu na região. Não existem pesquisas sobre os Sambas de Roda em Conceição do Jacuípe e seus respectivos grupos. Assim o presente artigo busca traçar um panorama histórico e cultural da cidade e dos grupos, no qual se destacam as performances, os instrumentos, os processos de socialização, bem como as principais festividades que se coadunam aos sambas. A partir do estudo 
da cidade é possível a própria problematização das concepções do que seja o "recôncavo", constatando também a importância da articulação política neste novo processo de patrimonialização em que o Samba de Roda foi inserido.

É importante ressaltar que esta articulação entre culturas populares e patrimônio é um fenômeno recente. Neste sentido, muito pouco tem se refletido nos trabalhos antropológicos sobre os impactos nos discursos de tradição que uma comunidade possui em suas relações com uma ideia de "Patrimônio Cultural do Brasil". E mais que isso, quais as implicações para as comunidades que ficam à margem deste processo. O Samba de Roda, atualmente, possui esta dimensão política e a falta desta articulação implica em processos de marginalização. A memória coletiva e os discursos de tradição são assim pensados para compreender as demandas políticas atuais dos Sambas de Roda, bem como o seu processo de construção social.

\section{Referências}

CASCUDO, Luís da Câmara. Dicionário do Folclore Brasileiro. São Paulo: Ediouro, 1998.

HALBWACHS, Maurice. A Memória Coletiva. São Paulo: Ed. Vértice, 1990.

HOBSBAWM, Eric; RANGER, Terence (Org.). A Invenção das Tradições. Rio de Janeiro: Paz e Terra, 1997.

IKEDA, Alberto T. Folia de Reis, Sambas do Povo, Ciclo de Reis em Goiânia: Tradição e Modernidade. Senri Ethnological Reports, Osaka, v. 1, 1994.

IPHAN. Samba de Roda do Recôncavo Baiano. Dossiê IPHAN 4. Brasília: Ministério da Cultura, 2007.

LIMA FILHO, M. F.; BELTRÃO, J. F.; ECKERT, C. Antropologia e patrimônio cultural: diálogos e desafios contemporâneos. Blumenau: Nova Letra, 2007.

MEIHY, José Carlos Sebe Bom. Manual de História Oral. 5. ed. São Paulo: Edições Loyola, 2005.

NOBRE, Cassio. Violas nos sambas do Recôncavo Baiano. 2008. 181fls. Dissertação (Mestrado em Música) - UFBA, Salvador, 2008.

ORTIZ, Renato. Cultura brasileira e Identidade nacional. São Paulo: Brasiliense, 2006. 
PERGO, Vera Lucia. Os rituais na folia de reis: uma das festas populares brasileiras. In: ENCONTRO DO GT NACIONAL DE HISTÓRIA DAS RELIGIÕES E RELIGIOSIDADES/ANPUH, 1., 2007, Maringá. Anais... Maringa, 2007.

REPPOLHO, Givaldo José dos Santos. Dicionário Ilustrado de Ritmos e Instrumentos de Percussão. Rio de Janeiro: GJS Editora, 2012.

SANDRONI, Carlos. Samba de Roda, patrimônio imaterial da humanidade. Estudos Avançados, São Paulo, v. 24, n. 69, 2010.

SANTOS, Myriam Sepúlveda. Memória Coletiva e Teoria Social. São Paulo: Annablume, 2003.

TAMASO, Izabela. A expansão do patrimônio: novos olhares sobre velhos objetos, outros desafios. Sociedade e Cultura, Goiânia, v.8, n.2, p. 13-36, 2005.

VANSINA, J. A tradição oral e sua metodologia. In: KI-ZERBO, Joseph (Ed.). História geral da África l: Metodologia e pré-história da África. Brasília: UNESCO, 2010. p. 139-166.

Recebido em 22.06.2014 - aprovado em 03.10.2014. 